\title{
Interfacial Reactions and Mechanical Properties of Sn-58Bi Solder Joints with Ag Nanoparticles Prepared Using Ultra-Fast Laser Bonding
}

\author{
Gyuwon Jeong 1,2, Dong-Yurl Yu 1,3, Seongju Baek 1,4® ${ }^{1}$, Junghwan Bang ${ }^{1}$, Tae-Ik Lee ${ }^{1}$, Seung-Boo Jung ${ }^{2}$, \\ JungSoo Kim ${ }^{1, *}$ and Yong-Ho Ko $1,5, *$ (i)
}

1 Advanced Functional Technology R\&D Department, Institute of Industrial Technology (KITECH), 156 Gaetbeol-ro, Yeonsu-gu, Incheon 21999, Korea; gyuwon@kitech.re.kr (G.J.); alpha0987@kitech.re.kr (D.-Y.Y.); back9457@kitech.re.kr (S.B.); nova75@kitech.re.kr (J.B.); tilee@kitech.re.kr (T.-I.L.)

2 School of Advanced Materials Science \& Engineering, Sungkyunkwan University, 2066 Seobu-Ro, Jangan-gu, Suwon, Gyeonggo-do 16419, Korea; sbjung@skku.edu

3 Department of Material Science and Engineering, Korea University, 145 Anam-ro, Seongbuk-gu, Seoul 02841, Korea

4 Department of Material Science and Engineering, Incheon National University, 119 Academy-ro, Yeonsu-gu, Incheon 22012, Korea

5 Department of Industrial Technology, University of Science and Technology, 217 Gajeong-ro, Yuseong-gu, Daejeon 34113, Korea

* Correspondence: kjs207@kitech.re.kr (J.K.); yonghoko@kitech.re.kr (Y.-H.K.)

Citation: Jeong, G.; Yu, D.-Y.; Baek, S.; Bang, J.; Lee, T.-I.; Jung, S.-B.; Kim, J.; Ko, Y.-H. Interfacial Reactions and Mechanical Properties of Sn-58Bi Solder Joints with Ag Nanoparticles Prepared Using Ultra-Fast Laser Bonding. Materials 2021, 14, 335. https://doi.org/10.3390/ma14020335

Received: 11 December 2020 Accepted: 4 January 2021

Published: 11 January 2021

Publisher's Note: MDPI stays neutral with regard to jurisdictional clai$\mathrm{ms}$ in published maps and institutional affiliations.

Copyright: (C) 2021 by the authors. Licensee MDPI, Basel, Switzerland. This article is an open access article distributed under the terms and conditions of the Creative Commons Attribution (CC BY) license (https:// creativecommons.org/licenses/by/ $4.0 /)$.

\begin{abstract}
The effects of Ag nanoparticle (Ag NP) addition on interfacial reaction and mechanical properties of $\mathrm{Sn}-58 \mathrm{Bi}$ solder joints using ultra-fast laser soldering were investigated. Laser-assisted low-temperature bonding was used to solder Sn-58Bi based pastes, with different Ag NP contents, onto organic surface preservative-finished $\mathrm{Cu}$ pads of printed circuit boards. The solder joints after laser bonding were examined to determine the effects of Ag NPs on interfacial reactions and intermetallic compounds (IMCs) and high-temperature storage tests performed to investigate its effects on the long-term reliabilities of solder joints. Their mechanical properties were also assessed using shear tests. Although the bonding time of the laser process was shorter than that of a conventional reflow process, $\mathrm{Cu}-\mathrm{Sn}$ IMCs, such as $\mathrm{Cu}_{6} \mathrm{Sn}_{5}$ and $\mathrm{Cu}_{3} \mathrm{Sn}$, were well formed the interface of the solder joint. The addition of Ag NPs also improved the mechanical properties of the solder joints by reducing brittle fracture and suppressing IMC growth. However, excessive addition of Ag NPs degraded the mechanical properties due to coarsened $\mathrm{Ag}_{3} \mathrm{Sn}$ IMCs. Thus, this research predicts that the laser bonding process can be applied to low-temperature bonding to reduce thermal damage and improve the mechanical properties of $\mathrm{Sn}-58 \mathrm{Bi}$ solders, whose microstructure and related mechanical properties can be improved by adding optimal amounts of Ag NPs.
\end{abstract}

Keywords: low-temperature bonding; laser process; Ag nanoparticle (Ag NP); interfacial reaction; intermetallic compounds (IMCs); mechanical property

\section{Introduction}

Recently, electronic devices have been used in microelectronic package technologies [1-3] with advanced capabilities, such as multi-functions, high densities of input/output, and high capacities. To achieve high performance and miniaturization, various packages are mounted on an electronic substrate. The mechanical properties of bonding joints between packages and printed circuit boards (PCBs) may degrade due to thermal damage and coefficient thermal expansion (CTE) mismatches in the coefficients of thermal expansion during multiple bonding processes. To solve these problems, local low-temperature bonding processes are required. 
Prior to the 2000s, Sn-Pb solder alloys were the most commonly used joint materials because of their excellent properties, such as wettability, low melting temperature, and cost competitiveness. However, the use of $\mathrm{Pb}$ was banned by the Restriction of Hazardous Substances Directive and Waste Electrical and Electronic Equipment because of its toxicity to humans and the environment [1-5]. Therefore, various kinds of $\mathrm{Pb}$-free Sn-based solder families, such as $\mathrm{Sn}-\mathrm{Ag}, \mathrm{Sn}-\mathrm{Cu}, \mathrm{Sn}-\mathrm{Zn}, \mathrm{Sn}-\mathrm{Bi}$, and $\mathrm{Sn}-\mathrm{In}$, have been developed to replace the $\mathrm{Sn}-\mathrm{Pb}$ solder [6-8]. Among these, $\mathrm{Sn}-\mathrm{Ag}-\mathrm{Cu}$ solder alloys are widely used as joint bonding materials. However, it is difficult to apply these alloys at low temperatures due to their high melting points $\left(217^{\circ} \mathrm{C}\right)[9,10]$. Therefore, $\mathrm{Pb}$-free solders with low melting temperatures, such Sn-Bi and Sn-In, have been used for low-temperature bonding. Sn-In solder alloys have limited application and productivity in the packaging industry owing to high cost $[7,9]$. Sn-Bi alloys have several advantages, such as high yield strength, creep resistance, and low cost [11]. However, the Sn-Bi solder also has disadvantages such as degradation of mechanical properties and poor reliabilities stemming from the $\mathrm{Bi}$. To overcome these drawbacks, researchers have tried to prevent coarsening and brittle fracture of $\mathrm{Bi}$ by adding elements or particles such as $\mathrm{Ag}$, $\mathrm{Sb}$, epoxy, and carbon nanotubes to $\mathrm{Sn}-58 \mathrm{Bi}$ solders [11-15]. In particular, the addition of Ag nanoparticles (Ag NPs) to $\mathrm{Sn}-58 \mathrm{Bi}$ solders is known to affect the microstructures in the bulk and reduce the growth of intermetallic compounds (IMCs) at the interface of the solder joint, which reduces diffusion of Bi and Sn [13].

Soldering, which is a reflow process based on surface mount technology, is the most commonly used process for bonding between some electronic packages and substrates for second level packaging. This is because soldering is capable of being used in mass production at low costs [16]. However, the conventional reflow process is difficult to use for bonding with miniaturized electronic components and may cause thermal damage [17-19]. Therefore, the abilities of laser bonding to reduce thermal damage by minimizing fast heating and bonding time has been studied [20]. In this process, applied to miniaturized electronic components, a laser can locally irradiate materials, such as electronic components, solder alloys, and substrates. In addition, a laser beam is rapidly generated by increasing the vibration energies of molecules in the materials in the packages. Thus, electronic components and substrates can be joined by transferring the heat generated in the substrates to bonding joints or solder joints between different components and substrates. This results in the completion of fabrication of second level packages in a much shorter process [21-23]. As a result, the laser process has many advantages, such as localized heating, shorter bonding time, and non-contact heating, compared to the conventional reflow soldering process. In addition, if a low-temperature solder like $\mathrm{Sn}-58 \mathrm{Bi}$ is used, it is possible to reduce the thermal damage and deterioration during laser bonding because of the low melting temperature of $\mathrm{Sn}-58 \mathrm{Bi}$ and the localized heating of the laser process. Previous studies $[17,22]$ have shown that the bonding strength from the laser bonding process was higher than that for the conventional reflow process. It was also confirmed that the IMC's thickness and grain size were smaller for laser bonding compared to those for the conventional reflow process due to the shorter bonding time of the former. However, studies showing improved mechanical properties of Sn-58Bi solder joints, which are currently brittle, are still lacking.

In this research, interfacial reactions and mechanical properties of the Ag NP reinforced Sn-58Bi solder with PCBs of organic surface preservative (OSP)-finished Cu pads were investigated. The joints were formed by using the laser soldering process. To examine the effects of adding different amounts of Ag NPs to the Sn-58Bi solder on the properties of the joints, microstructures in the solder bulk and IMCs produced by reactions at the interface were analyzed. In addition, shear tests were performed on the Ag NP reinforced Sn-58Bi solder at two different speeds to evaluate the mechanical properties of the joints. To analyze long-term reliability, high-temperature storage (HTS) tests were also conducted at three different temperatures. After the HTS tests, the effects of Ag NPs on joint properties, such 
as microstructures, interfacial reactions, IMC growth, and mechanical properties, were also analyzed and related to different Ag NP contents and different HTS test conditions.

\section{Materials and Methods}

For this study, Sn-58Bi composite solder pastes with added Ag NPs were fabricated using Sn-58Bi solder powders (20-38 $\mu$ m; Avention, Incheon, Korea), Ag NPs (20 nm; Avention, Korea), and a low-temperature flux (CVP-520, Alpha Co., Somerset, NJ, USA). The compositions of the solder pastes are given in Table 1. It was weighted on a scale (Practum224-1SKR, Göttingen, Neddersassen, Germany). To make the pastes, the flux was first mixed with Ag NPs to correspond to $0.0 \mathrm{wt} . \%, 0.5 \mathrm{wt} . \%, 0.75 \mathrm{wt} . \%, 1.0 \mathrm{wt} . \%$, and $2.0 \mathrm{wt} . \%$ of Ag NPs. Mixing was carried out for $5 \mathrm{~min}$ at a speed of 800 revolutions per minute (RPM) under revolution and rotation using a paste mixer (paste mixer; PDM-300V, Daewhatech, Yongin, Korea). The solder powders were then mixed with flux and Ag NPs. The composite solder pastes were printed on OSP-finished $\mathrm{Cu}$ pads with a diameter of $300 \mu \mathrm{m}$ on the flame retardant 4 (FR-4) PCB substrates. A screen-printing method was used with a stencil mask with a thickness of $100 \mu \mathrm{m}$ and an open size of $760 \mu \mathrm{m}$ (Figure 1). After the $\mathrm{Sn}-58 \mathrm{Bi} \mathrm{Ag}$ NP composite solder paste was printed onto the $\mathrm{Cu}$ pads on the $\mathrm{PCB}$, a laser soldering process was performed for $4 \mathrm{~s}$ at a peak temperature of $158^{\circ} \mathrm{C}$ (laser power of $150 \mathrm{~W}$ ) using a laser energy source (CW Fiber lasers, IPG Photonics, Oxford, MA, USA). After the laser solder process and the formation of solder joints, flux residues were removed and cleaned using a de-flux solution. The fabrication process and the conditions of the laser soldering process are shown schematically in Figure 1.

Table 1. Compositions of solder pastes.

\begin{tabular}{ccc}
\hline \multirow{2}{*}{ Specimens } & \multicolumn{2}{c}{ wt.\% } \\
\cline { 2 - 3 } & Ag NP & Sn-58Bi Powder \\
\hline$\# 1$ & 0.0 & 100.0 \\
$\# 2$ & 0.5 & 99.5 \\
$\# 3$ & 0.75 & 99.25 \\
$\# 4$ & 1.0 & 99.0 \\
$\# 5$ & 2.0 & 98.0 \\
\hline
\end{tabular}

To analyze how the joint properties changed with the addition of Ag NPs, scanning electron microscopy (SEM; Inspect F, FEI Co., Hillsboro, OR, USA) and energy-dispersive spectrometry (EDS; superdry, Thermo Noran Co., Waltham, MA, USA) were performed to observe the microstructure, interfacial reaction, and IMC formation at the interface of the solder bulk and solder joints. The mechanical properties of the solder joints were evaluated under two shear test conditions. The shear tests were performed at two shear speeds of 0.1 and $1.0 \mathrm{~m} / \mathrm{s}$ with a shear height of $50 \mu \mathrm{m}$ using a high-speed shear tester (Dage 4000 HS; Nordson Co., Aylesbury, Buckinghamshire, UK). In the case of a shear speed of $0.1 \mathrm{~m} / \mathrm{s}$, the general shear strength was confirmed, and in the case of a shear speed of $1 \mathrm{~m} / \mathrm{s}$, the impact mechanical property was measured. Low- and high-speed shear tests were performed according to the Joint Electron Device and Engineering Council (JEDEC) 22-B117A standards. In addition, the fracture surfaces were investigated after the shear test, and the additional effect of Ag NPs on the mechanical properties was analyzed using SEM and EDS. 

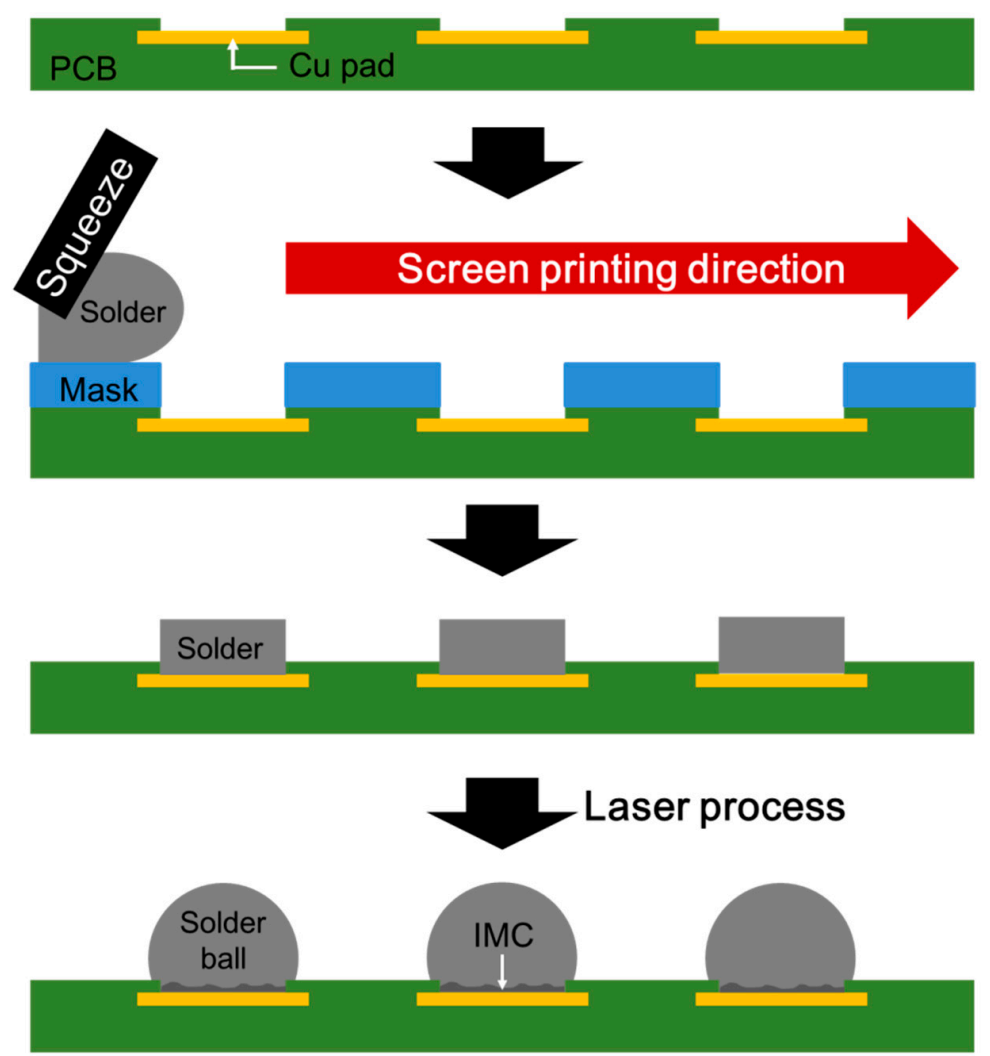

(a)

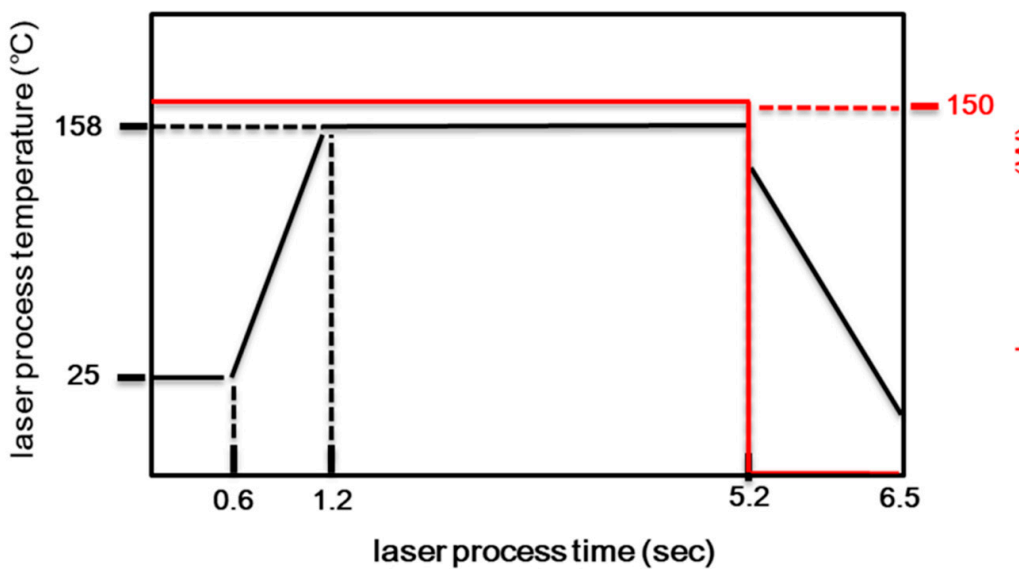

(b)

Figure 1. (a) Schematic of the fabrication process for test samples and (b) profiles for bonding conditions by the laser process.

HTS tests were conducted to analyze the effect of Ag NPs on the long-term reliabilities of the laser processed solders. The HTS tests were performed for $1000 \mathrm{~h}$ at three temperatures: 85,100 , and $115^{\circ} \mathrm{C}$. This environmental reliability test was based on the JEDEC JESD-47 and JESD-A103E standards. After the HTS tests, the effects of the addition of Ag NPs on the microstructures, formation of IMCs, and mechanical properties were investigated. The effects of Ag NP content and the temperature conditions on the thickness and growth of the IMCs were also analyzed during the HTS tests.

\section{Results and Discussion}

Figure 2 shows cross-sectional SEM micrographs of the solder joints with different Ag NP contents during the HTS test at $85{ }^{\circ} \mathrm{C}$ for $1000 \mathrm{~h}$. After reflow, a $\mathrm{Cu}_{6} \mathrm{Sn}_{5} \mathrm{IMC}$ 
layer formed at the interface between the Sn-58Bi solder and the OSP-finished Cu pads regardless of the Ag NP content in the solder pastes. The Sn and Bi elements formed eutectic lamellar structures in the $\mathrm{Sn}-58 \mathrm{Bi}$ solder because of the similar volume percent of $\mathrm{Sn}$ and $\mathrm{Bi}[15,24]$. The initial $\mathrm{Cu}_{6} \mathrm{Sn}_{5} \mathrm{IMC}$ layer thicknesses did not vary significantly from 0.0 to $2.0 \mathrm{wt}$.\% Ag NPs, with values of $0.25,0.24,0.21,0.20$, and $0.22 \mu \mathrm{m}$. However, the $\mathrm{Cu}_{6} \mathrm{Sn}_{5}$ IMC layer thicknesses were increased with increasing HTS time. In addition, a plate-type $\mathrm{Ag}_{3} \mathrm{Sn}$ IMC was formed by the addition of Ag NPs after HTS for $100 \mathrm{~h}$. The cross-sectional SEM micrographs of the Sn-58Bi Ag NP composite solder joints after the HTS test at $100{ }^{\circ} \mathrm{C}$ for $1000 \mathrm{~h}$ are shown in Figure 3. As the HTS time increased, the $\mathrm{Cu}_{6} \mathrm{Sn}_{5} \mathrm{IMC}$ layers of the solder joints treated at $100{ }^{\circ} \mathrm{C}$ were thicker than those treated at $85^{\circ} \mathrm{C}$. The total $\mathrm{Cu}-\mathrm{Sn}$ IMC layer thickness decreased with increasing Ag NP content. Island-type $\mathrm{Cu}_{3} \mathrm{Sn}$ IMC was observed at the interface between the $\mathrm{Cu}_{6} \mathrm{Sn}_{5} \mathrm{IMC}$ layer and the OSP-finished $\mathrm{Cu}$ pad of the Sn-58Bi solder joint without Ag NPs after $500 \mathrm{~h}$ under the HTS test. For solders with Ag NP contents above $0.5 \mathrm{wt} . \%$, after $750 \mathrm{~h}, \mathrm{Cu}_{3} \mathrm{Sn}$ IMC was observed. The $\mathrm{Cu}_{6} \mathrm{Sn}_{5} \mathrm{IMC}$ was then decomposed into $\mathrm{Cu}_{3} \mathrm{Sn}$ IMC and $\mathrm{Sn}$ to form $\mathrm{Cu}_{3} \mathrm{Sn}$ IMC at the interface $[25,26]$. In the case of the Sn-58Bi Ag NP composite solder, it is thought that the formation of $\mathrm{Cu}_{6} \mathrm{Sn}_{5}$ IMC was suppressed by $\mathrm{Ag}_{3} \mathrm{Sn}$ IMC, and the growth of $\mathrm{Cu}_{3} \mathrm{Sn}$ IMC was also suppressed.

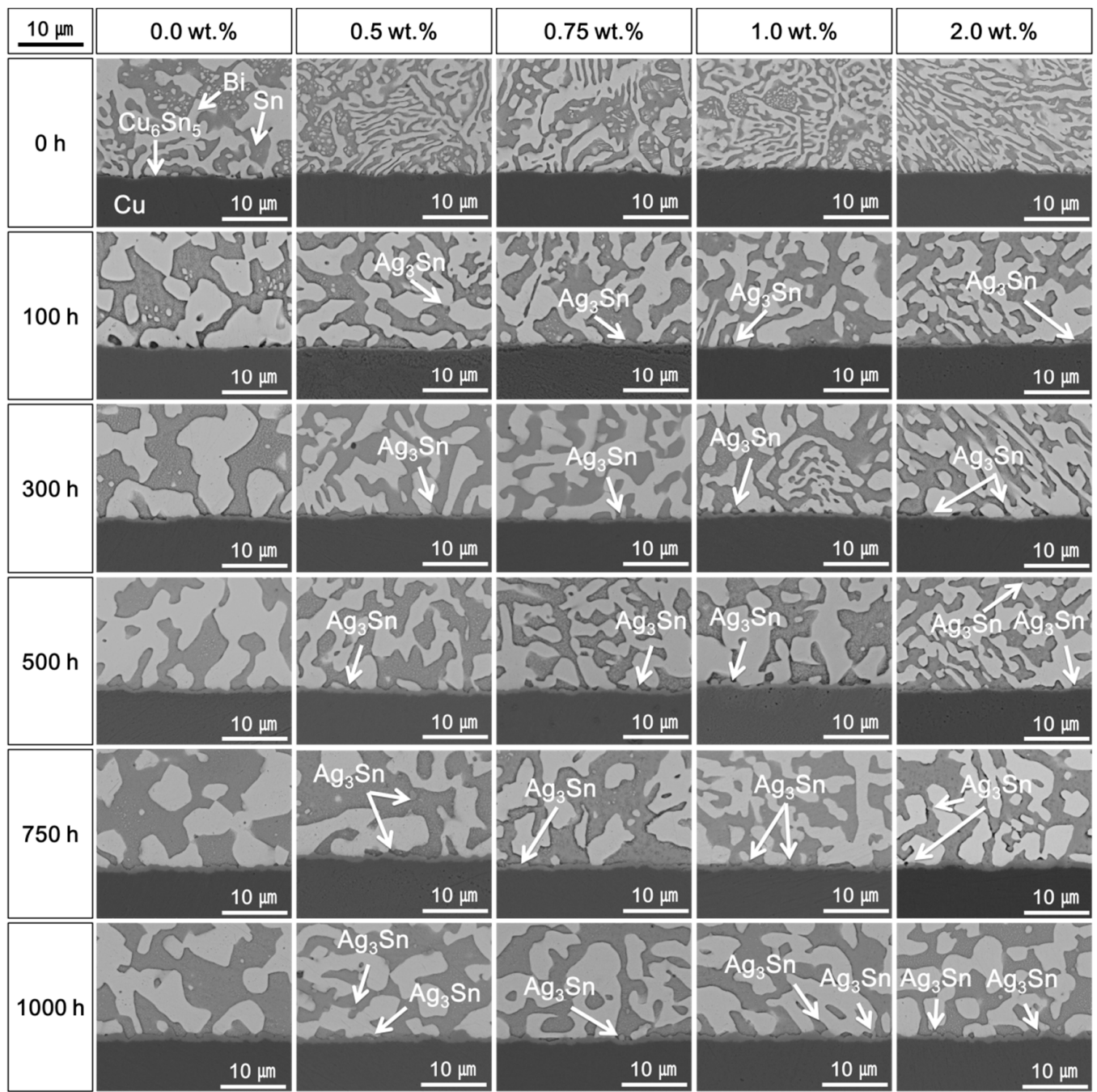

Figure 2. Cross-sectional scanning electron microscopy (SEM) micrographs of the Sn-58Bi Ag NP composite solder joints after high-temperature storage (HTS) tests at $85^{\circ} \mathrm{C}$. 


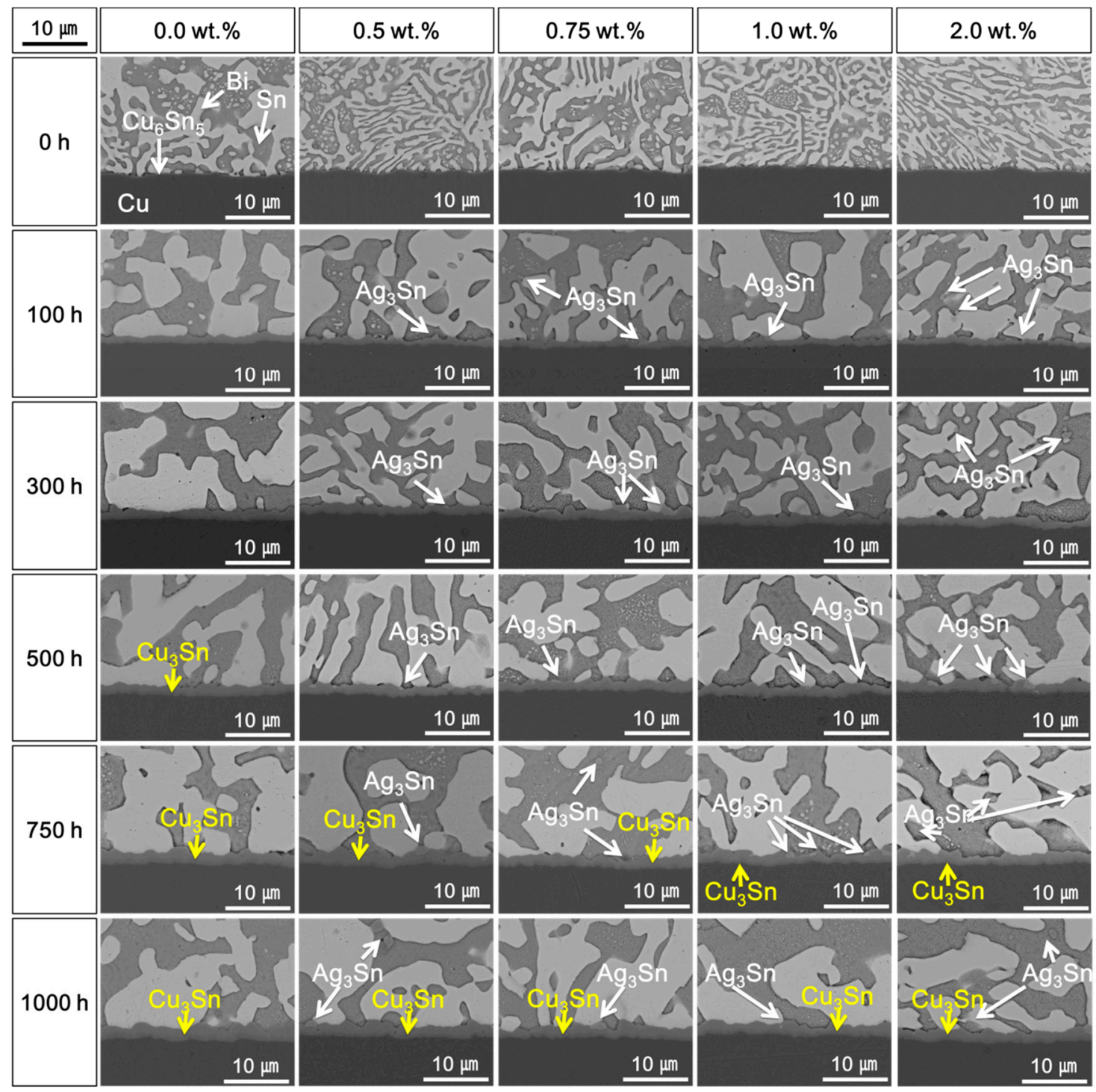

Figure 3. Cross-sectional scanning electron microscopy (SEM) micrographs of the Sn-58Bi Ag NP composite solder joints after high-temperature storage (HTS) tests at $100^{\circ} \mathrm{C}$.

Figure 4 also shows SEM micrographs of the cross-sectioned solder joints after $1000 \mathrm{~h}$ at $115^{\circ} \mathrm{C}$. In the samples without $\mathrm{Ag} \mathrm{NPs}, \mathrm{Cu}_{3} \mathrm{Sn}$ IMC was formed at the interface between the $\mathrm{Cu}_{6} \mathrm{Sn}_{5} \mathrm{IMC}$ and $\mathrm{Cu}$ substrate after $500 \mathrm{~h}$. With increasing Ag NP content, the IMC's thickness decreased. Regardless of the temperatures for the HTS tests, the IMC thicknesses and the IMC growth decreased with increasing Ag NP content. It is assumed that the Ag $\mathrm{NPs}$ affected the refining of the $\mathrm{Sn}-\mathrm{Bi}$ microstructure and formed $\mathrm{Ag}_{3} \mathrm{Sn}$ IMC. This means that the $\mathrm{Ag}_{3} \mathrm{Sn}$ IMCs could suppress grain coarsening and IMC growth. According to a previous report, the IMC shape at the interface of the solder joint can be improved to form a scalloped IMC more uniformly when the $\mathrm{Ag}_{3} \mathrm{Sn}$ nanoparticles are placed appropriately. However, the IMCs thickness can increase when excessive $\mathrm{Ag}_{3} \mathrm{Sn}$ is added [27]. 


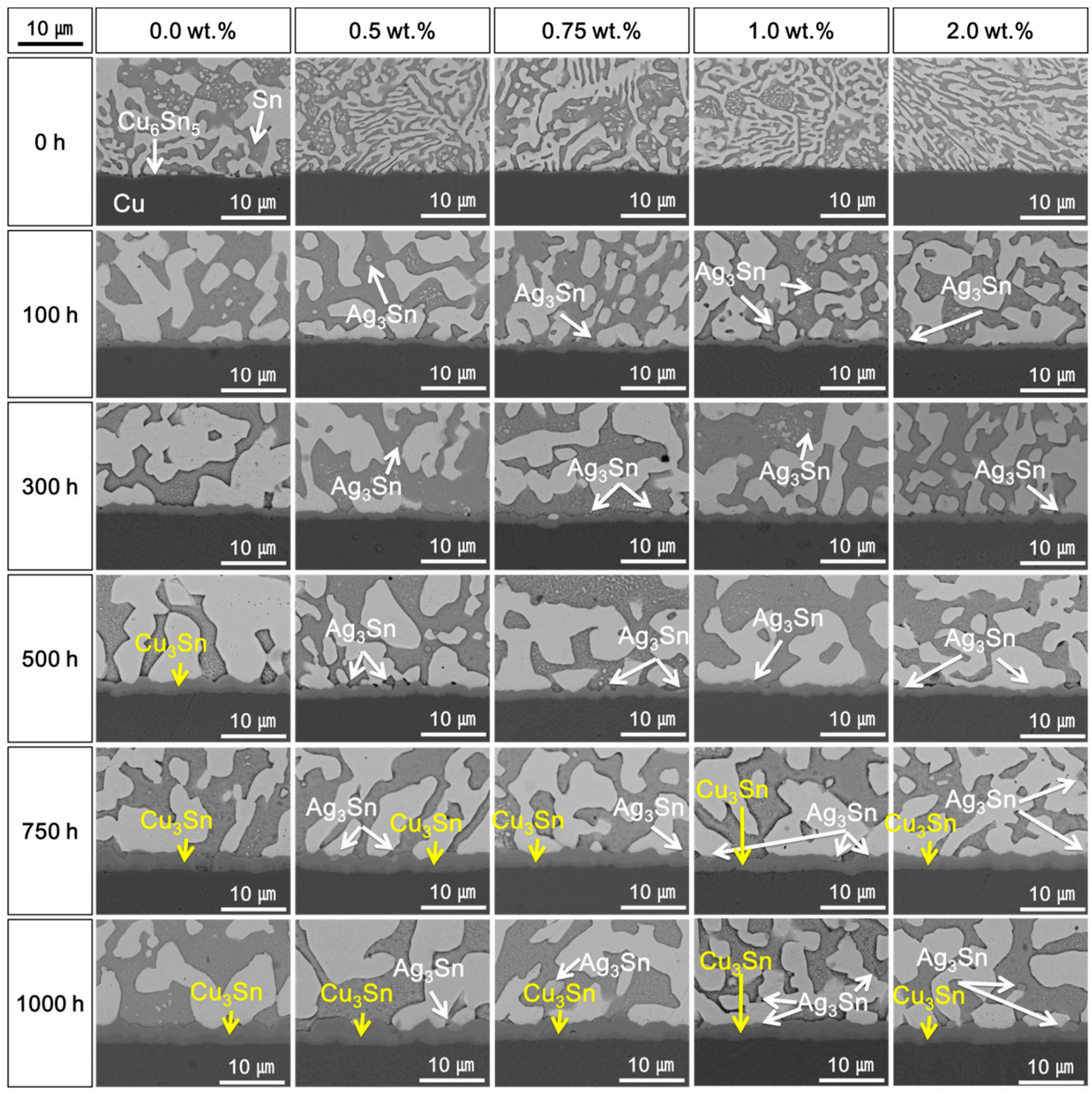

Figure 4. Cross-sectional scanning electron microscopy (SEM) micrographs of the Sn-58Bi Ag NP composite solder joints after high-temperature storage (HTS) tests at $115^{\circ} \mathrm{C}$.

The $\mathrm{Cu}-\mathrm{Sn}$ IMC thicknesses in Sn-58Bi Ag NP composite solder joints as functions of the HTS test time and temperature are shown in Figure 5. The initial thickness of the $\mathrm{Cu}-\mathrm{Sn}$ IMC did not change significantly with Ag NP content. The thicknesses of the IMCs increased with increasing test times and temperatures in the HTS tests. However, the growths and thicknesses of IMCs were smaller and slower in the solders containing Ag NPs compared to those without Ag NPs. We calculated activation energies to analyze the IMC growth rate of the Ag NP reinforced Sn-58Bi solder joints [28]. 


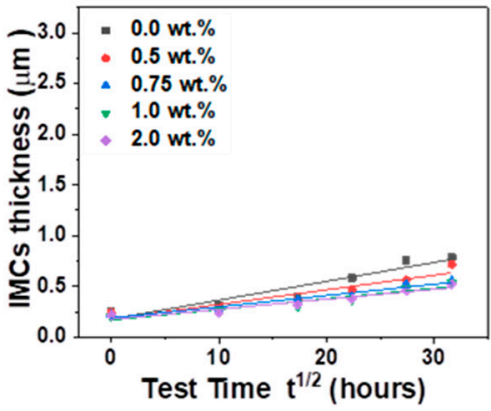

(a)

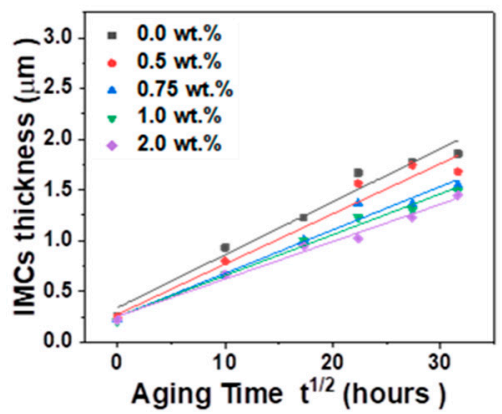

(b)

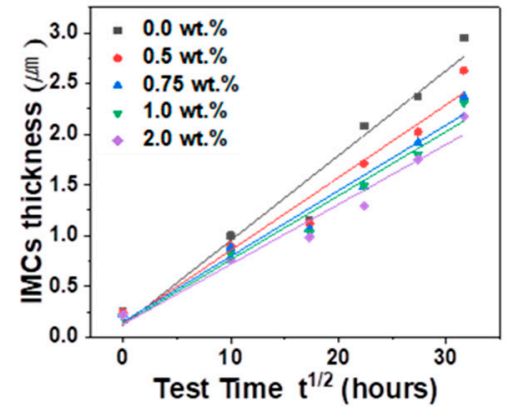

(c)

Figure 5. Total intermetallic compounds (IMCs) thickness as a function of test time at temperatures: $\left(\right.$ a) $85^{\circ} \mathrm{C}(\mathbf{b}) 100{ }^{\circ} \mathrm{C}$, and (c) $115^{\circ} \mathrm{C}$.

The relationship between IMC's thickness and test time follows the Equation (1):

$$
w=k t^{n}
$$

where $w$ is the IMCs thickness, $k$ the growth rate constant, $t$ the test time, and $n$ the time exponent. In addition, the activation energy required for IMC growth can be calculated in the solder joint by the following Arrhenius equation:

$$
k^{2}=k_{0}^{2} \exp \left(-\frac{Q}{R T}\right),
$$

where $k^{2}$ is the square of the growth rate constant, $k_{0}$ the frequency factor, $Q$ the activation energy, $R$ the gas constant $(8.314 \mathrm{~J} / \mathrm{mol} \cdot \mathrm{K})$, and $T$ the aging temperature in Kelvin $(\mathrm{K})$.

$$
\ln \left(k^{2}\right)=\ln \left(k_{0}^{2}\right)-\frac{Q}{R T}
$$

Equation (2) can also be converted to Equation (3) by taking the logarithms of both sides of Equation (2). Therefore, the Arrhenius plots were used to determine the activation energy for the growth of the IMCs during the HTS tests. These are shown in Figure 6. The activation energies were $115.6 \mathrm{~kJ} / \mathrm{mol}$ for $\mathrm{Sn}-58 \mathrm{Bi}, 123.6 \mathrm{~kJ} / \mathrm{mol}$ for $\mathrm{Sn}-58 \mathrm{Bi}-0.5 \mathrm{Ag}$, $135.9 \mathrm{~kJ} / \mathrm{mol}$ for $\mathrm{Sn}-58 \mathrm{Bi}-0.75 \mathrm{Ag}, 138.7 \mathrm{~kJ} / \mathrm{mol}$ for $\mathrm{Sn}-58 \mathrm{Bi}-1.0 \mathrm{Ag}$, and $138.0 \mathrm{~kJ} / \mathrm{mol}$ for $\mathrm{Sn}-58 \mathrm{Bi}-2.0 \mathrm{Ag}$. Therefore, the activation energy changed significantly with change in Ag NP content. It was assumed that IMC growth was inhibited by increased activation energies as the content of Ag NPs increased. According to previous studies, the activation energy between the $\mathrm{Sn}$ and 58Bi solder and the $\mathrm{Cu}$ substrate at $70-120{ }^{\circ} \mathrm{C}$ was about $127 \mathrm{~kJ} / \mathrm{mol}[29,30]$. In a previous study, adding $3 \mathrm{wt} . \%$ of $\mathrm{Y}_{2} \mathrm{O}_{3}$ to the $\mathrm{Sn}-58 \mathrm{Bi}$ solder increased the activation energy for $\mathrm{Cu}_{6} \mathrm{Sn}_{5}$ IMC growth by $14 \%$ when bonding on a $\mathrm{Cu}$ substrate [31]. However, in our study, the activation energy was increased by approximately $20 \%$ upon the addition of $2.0 \mathrm{wt}$. $\%$ Ag NP to the Sn-58Bi solder. 


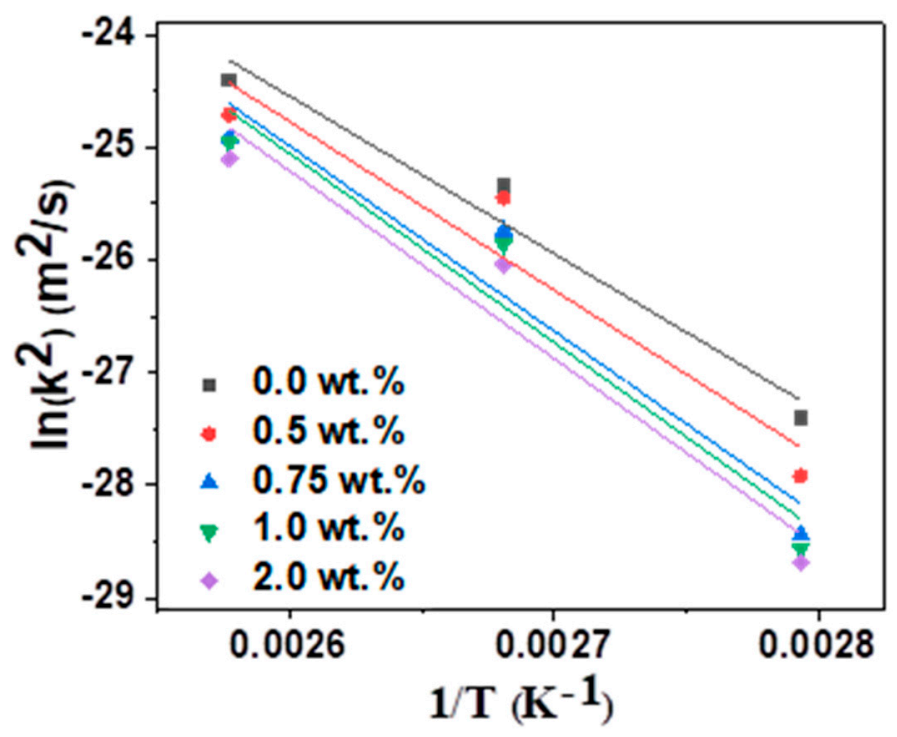

Figure 6. Arrhenius plots of intermetallic compound (IMC) growth rate as a function of Ag NP content of $\mathrm{Sn}-58 \mathrm{Bi}$ solder.

Figure 7 shows the results of the shear tests at two shear speeds of 1.0 and $0.1 \mathrm{~m} / \mathrm{s}$. Results for different contents of Ag NP after HTS test at 85, 100, and $115{ }^{\circ} \mathrm{C}$ for $1000 \mathrm{~h}$ are presented. Overall, the Sn-58Bi composite solders with Ag NP showed higher shear strengths than the Sn-58Bi solder without Ag NP. Figure 7a shows the shear strength after the HTS test at $85^{\circ} \mathrm{C}$. The shear strength values of the $\mathrm{Sn}-58 \mathrm{Bi}$ composite solder with $0.75 \mathrm{wt} . \% \mathrm{Ag}$ NP were 6.0 and $5.3 \mathrm{~N}$ at 1.0 and $0.1 \mathrm{~m} / \mathrm{s}$, respectively, which were higher than those of other Ag NP contents. The shear strength values after the HTS test at $100{ }^{\circ} \mathrm{C}$ were approximately 5.9 and $5.1 \mathrm{~N}$ for $0.75 \mathrm{wt} . \% \mathrm{Ag} \mathrm{NP}$ Sn-58Bi composite solder joint at shear speeds of 1.0 and $0.1 \mathrm{~m} / \mathrm{s}$, respectively (Figure $7 \mathrm{~b}$ ). However, after $1000 \mathrm{~h}$ at $115^{\circ} \mathrm{C}$, as shown in Figure 7c, the shear strength of the Sn-58Bi Ag NP composite solder joint with $1.0 \mathrm{wt} . \% \mathrm{Ag} \mathrm{NP}$ was the highest. Moreover, the shear strengths of the solder joints were decreased with increasing test times regardless of the contents of Ag NP and the temperature conditions of the HTS tests.
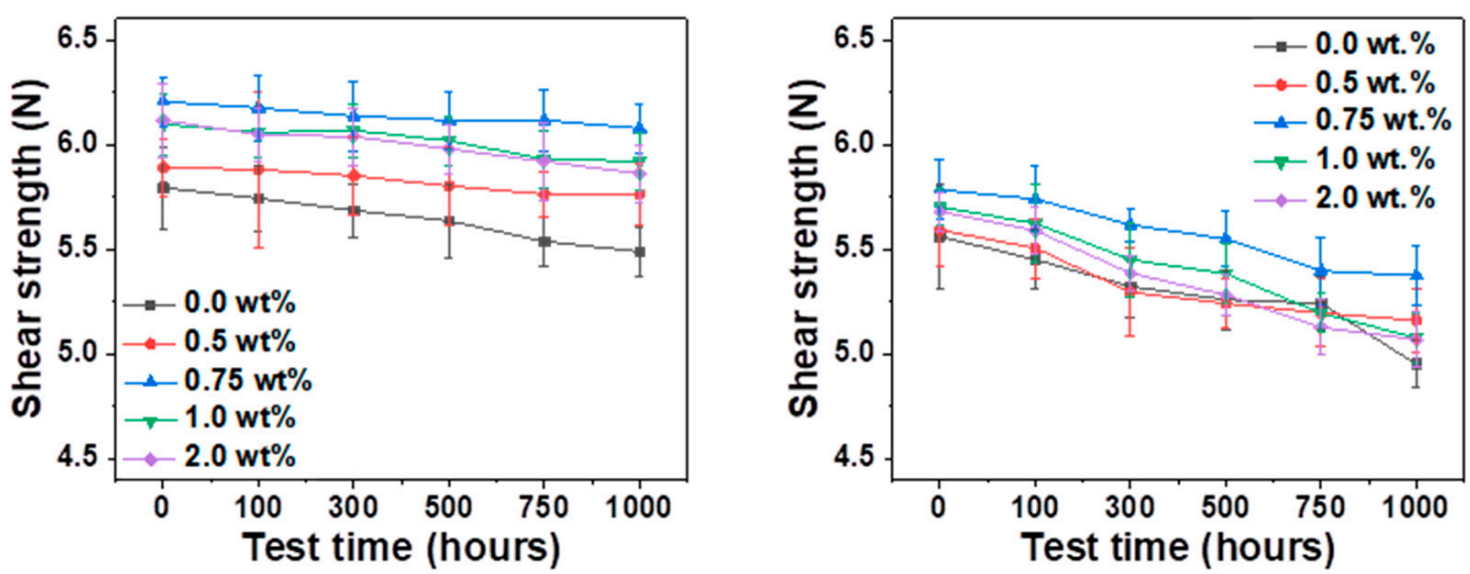

(a)

Figure 7. Cont. 

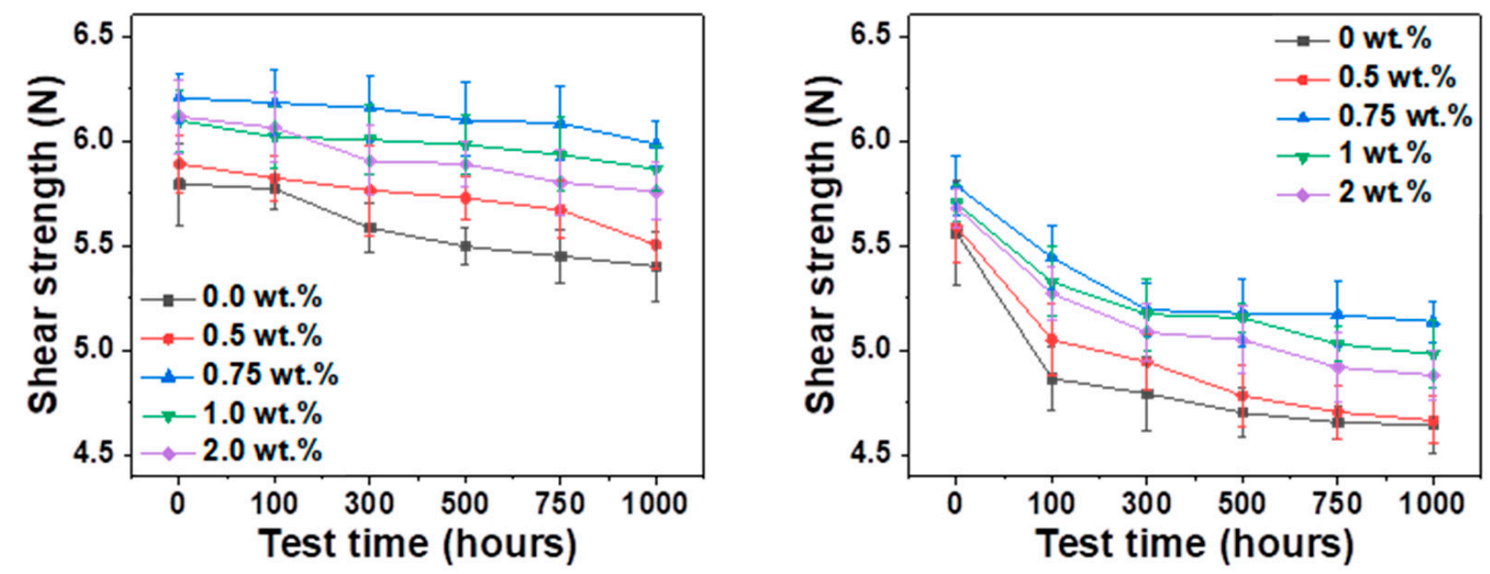

(b)
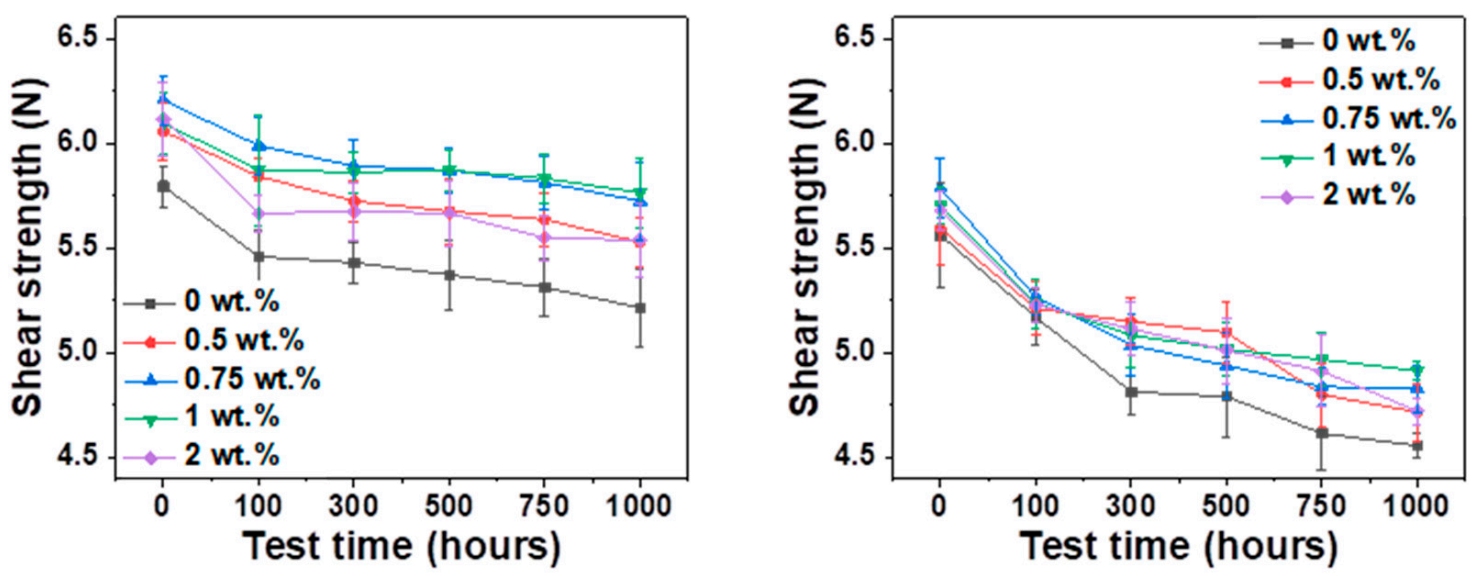

(c)

Figure 7. Shear strengths of $\mathrm{Sn}-58 \mathrm{Bi}$ composite solder joints with the test times and Ag NP contents after a high-temperature storage (HTS) tests at (a) $85^{\circ} \mathrm{C}$, (b) $100{ }^{\circ} \mathrm{C}$, and (c) $115^{\circ} \mathrm{C}$.

Figures 8-10 shows the top-view SEM micrographs of fracture surfaces after the shear tests performed during the HTS tests at 85,100 , and $115^{\circ} \mathrm{C}$. Both ductile fracture in the solder and brittle fracture at the $\mathrm{Cu}-\mathrm{Sn}$ IMC layer occurred, and the two fracture modes were mixed under all conditions of the HTS tests and contents of Ag NP. At the initial stage after laser soldering, ductile fracture was dominant, and the addition of Ag NP did not significantly affect the fracture mode. The brittle fracture dimensions at the IMC surface increased with increasing HTS time and temperature, regardless of the Ag NP content. However, it was observed that the brittle fractures were suppressed when the Ag NPs were added to the Sn-58Bi solder. As shown in Figures 8-10, the brittle fracture dimensions of solder joints with Ag NP were relatively small compared to those without Ag NP. In addition, the effects of the Ag NP increased as the lengths and temperatures of the HTS test were increased. 


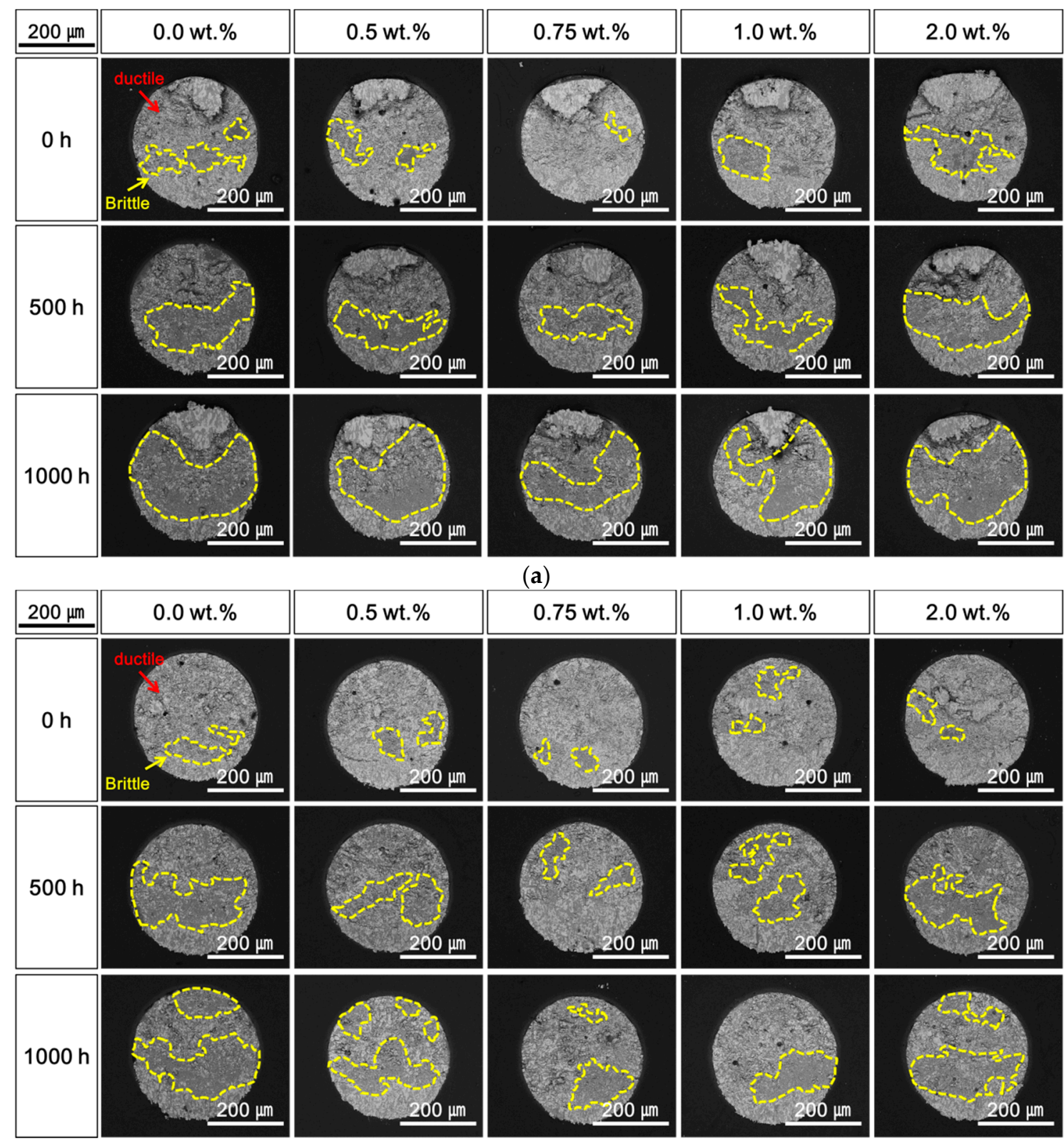

(b)

Figure 8. Top-view scanning electron microscopy (SEM) micrographs of fracture surfaces after a high-temperature storage (HTS) test at $85^{\circ} \mathrm{C}:(\mathbf{a}) 0.1 \mathrm{~m} / \mathrm{s}$ and (b) $1.0 \mathrm{~m} / \mathrm{s}$. 

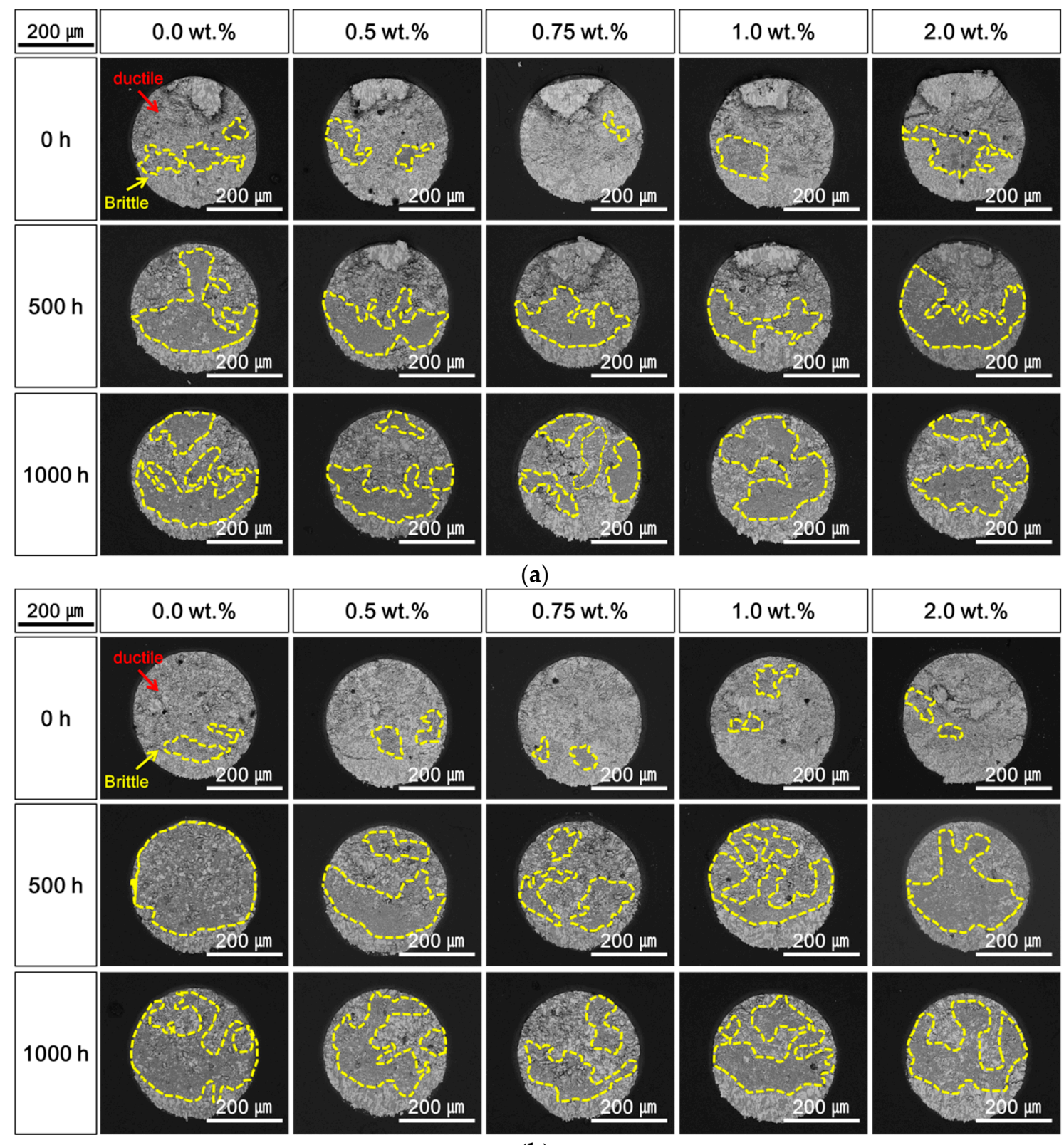

(b)

Figure 9. Top-view scanning electron microscopy (SEM) micrographs of fracture surfaces after a high-temperature storage (HTS) test at $100{ }^{\circ} \mathrm{C}:(\mathbf{a}) 0.1 \mathrm{~m} / \mathrm{s}$ and (b) $1.0 \mathrm{~m} / \mathrm{s}$. 


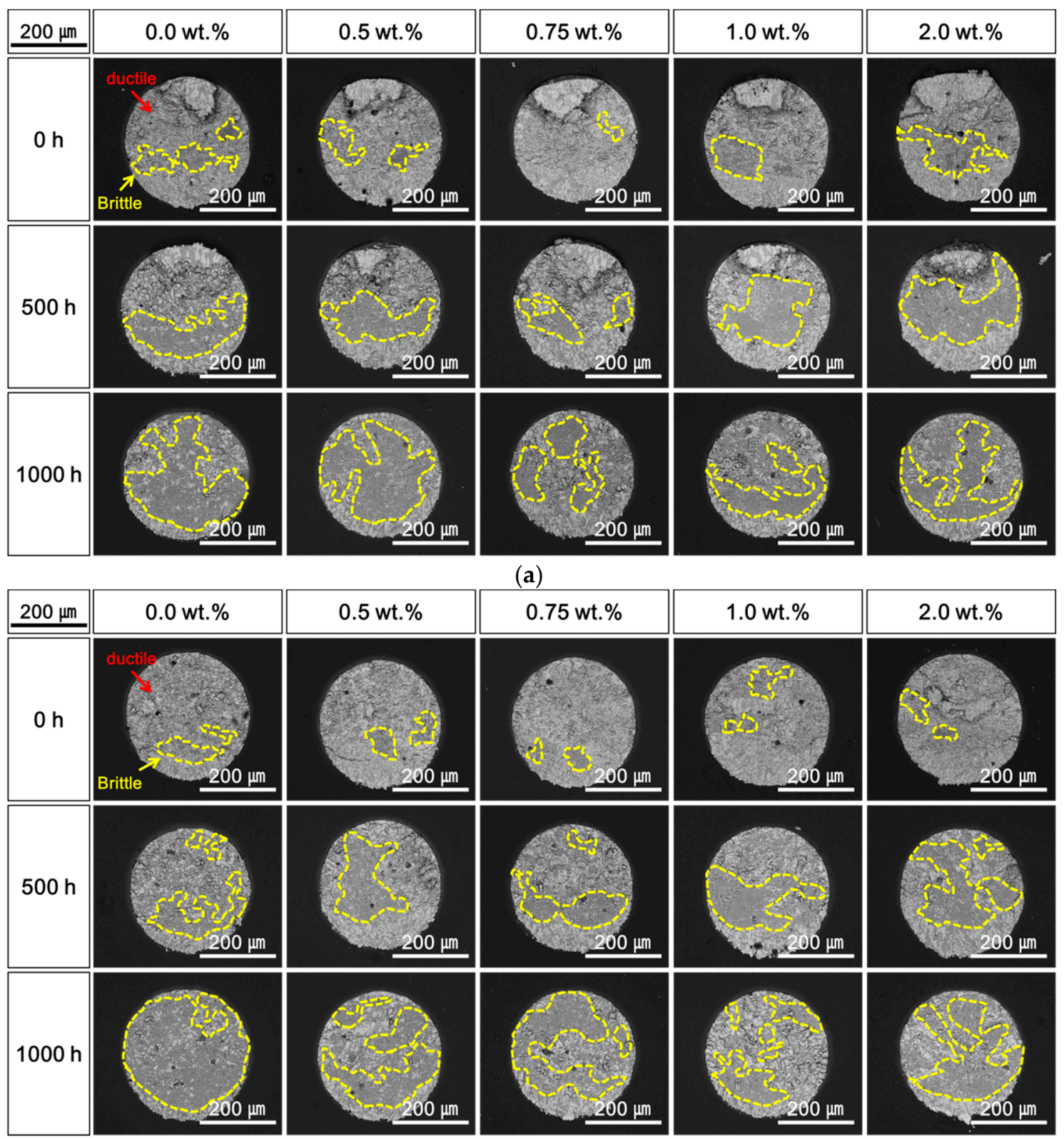

(b)

Figure 10. Top-view scanning electron microscopy (SEM) micrographs of fracture surfaces after a high-temperature storage (HTS) test at $115^{\circ} \mathrm{C}:(\mathbf{a}) 0.1 \mathrm{~m} / \mathrm{s}$ and (b) $1.0 \mathrm{~m} / \mathrm{s}$.

However, increases in the brittle fractures at the IMC layers were observed as the content of Ag NPs further increased up to $1.0 \mathrm{wt} . \%$. The shear strengths of the solder joints also decreased when the Ag NP was $2.0 \mathrm{wt} . \%$. As shown in Figures 2-4, the $\mathrm{Ag}_{3} \mathrm{Sn}$ IMCs were formed in the solder and on the IMC layer at the interface of solder joints. This research assumed that coarsened $\mathrm{Ag}_{3} \mathrm{Sn}$ IMCs with increasing Ag NP content could adversely affect the shear strength and degrade the mechanical properties. In a previous study, the $\mathrm{Ag}_{3} \mathrm{Sn}$ was increased with increasing Ag NP content. However, the thickness of $\mathrm{Cu}-\mathrm{Sn}$ IMCs such as $\mathrm{Cu}_{6} \mathrm{Sn}_{5}$ and $\mathrm{Cu}_{3} \mathrm{Sn}$ was thin, and the study reported that the addition of a specific amount of additives improves mechanical properties [14,15]. However, when the additive content exceeds a critical point, mechanical properties can be adversely affected. Therefore, our results were consistent with those of the previous study. 
From our results in this research, a laser soldering method under low-temperature bonding was proposed, and its applicability to electronic packaging was confirmed. This research found the addition of Ag NPs suppresses IMC growth, which affects the increase in the activation energies. This research also observed that the addition of Ag NPs could improve the mechanical properties of solder joints in shear after HTS tests by decreasing brittle fracture due to inhibition of IMC growth [30,32]. However, this research also observed that the excessive addition of Ag NPs degrades the mechanical properties of the $\mathrm{Sn}-58 \mathrm{Bi}$ solder joint. Therefore, the addition of Ag NPs in the range from 0.5 to $1.0 \mathrm{wt} . \%$ using a laser process in the $\mathrm{Sn}-58 \mathrm{Bi}$ solder joint can improve the mechanical properties of the $\mathrm{Sn}-58 \mathrm{Bi}$ solder joint for low-temperature bonding of electronic packaging.

\section{Conclusions}

We investigated the interfacial reactions and mechanical properties of solder joints between $\mathrm{Sn}-58 \mathrm{Bi}$ solders, with and without the addition of 0 to $2.0 \mathrm{wt} . \% \mathrm{Ag} \mathrm{NPs}$, and OSP-finished $\mathrm{Cu}$, formed using a laser bonding method. $\mathrm{Cu}-\mathrm{Sn} \mathrm{IMCs}$ as $\mathrm{Cu}_{6} \mathrm{Sn}_{5}$ and $\mathrm{Cu}_{3} \mathrm{Sn}$, were formed at the interface, even though the bonding times of the laser process were very short compared to the conventional reflow process. With increasing Ag NP content, the growth of $\mathrm{Cu}-\mathrm{Sn}$ IMCs was suppressed, and the activation energies for the formation of $\mathrm{Cu}-\mathrm{Sn}$ IMCs increased, regardless of the HTS temperature. It is inferred that $\mathrm{Ag}_{3} \mathrm{Sn}$ IMCs formed and that these IMCs could disturb the diffusion of $\mathrm{Sn}$ and $\mathrm{Cu}$, which inhibited the growth of $\mathrm{Cu}-\mathrm{Sn} I M C s$. Both $\mathrm{Cu}_{6} \mathrm{Sn}_{5}$ and $\mathrm{Cu}_{3} \mathrm{Sn}$ IMCs were observed at the interface as the HTS temperatures and times were increased, while only $\mathrm{Cu}_{6} \mathrm{Sn}_{5} \mathrm{IMCs}$ were formed after laser soldering. The addition of Ag NP to the Sn-58Bi solder joint improved the mechanical properties of the solder joints, as measured by shear tests, by significantly decreasing the brittle fracture due to reduced IMCs thickness. In all HTS tests at $1000 \mathrm{~h}$, the Sn-58Bi composite solder with $0.75 \mathrm{wt} . \% \mathrm{Ag}$ NP was $1 \mu \mathrm{m}$ thinner than the Sn-58Bi solder, and the shear strength was about $7 \%$ higher. However, excessive addition of Ag NPs to $1.0 \mathrm{wt} . \%$ adversely affected the mechanical properties of the solder joint because the $\mathrm{Ag}_{3} \mathrm{Sn}$ IMCs coarsened at the interface and in the solder.

Author Contributions: Conceptualization, S.-B.J.; J.K. and Y.-H.K.; Data curation, G.J. and S.B.; Formal analysis, J.B.; T.-I.L. and S.-B.J.; Investigation, G.J. and D.-Y.Y.; Methodology, D.-Y.Y. and T.-I.L.; Project administration, Y.-H.K.; Writing—original draft, J.K.; Writing-review \& editing, Y.-H.K. All authors have read and agreed to the published version of the manuscript.

Funding: This research was funded by Korea Institute of Industrial Technology (KITECH), Republic of Korea.

Data Availability Statement: Data sharing is not applicable to this article.

Acknowledgments: This study has been conducted with the support of the Korea Institute of Industrial Technology as "Development of root technology for multi-product flexible production (kitech EO-20-0015, 2020/2021)".

Conflicts of Interest: The authors declare no conflict of interest.

\section{References}

1. Choudhury, D. 3D integration technologies for emerging microsystems. In Proceedings of the 2010 IEEE MTT-S International Microwave Symposium, Anaheim, CA, USA, 23-28 May 2010; IEEE: Piscataway, NJ, USA, 2010; pp. 1-4. [CrossRef]

2. Zhu, Z.; Chan, Y.-C.; Wu, F. Failure mechanisms of solder interconnects under current stressing in advanced electronic packages: An update on the effect of alternating current (AC) stressing. Microelectron. Reliab. 2018, 91, 179-182. [CrossRef]

3. Lin, J.; Lei, Y.; Wu, Z.; Yin, L. Comparison investigation of thermal fatigue and mechanical fatigue behavior of board level solder joint. In Proceedings of the 2009 International Conference on Electronic Packaging Technology \& High Density Packaging, Xi'an, China, 16-19 August 2010; IEEE: Piscataway, NJ, USA, 2010; Volume 42, pp. 1179-1182. [CrossRef]

4. Ma, H.; Suhling, J.C. A review of mechanical properties of lead-free solders for electronic packaging. J. Mater. Sci. 2009, 44, 1141-1158. [CrossRef] 
5. Ozaki, S.; Take, Y.; Adachi, S. Optical properties and electronic energy-band structure of CdIn2Te4. J. Mater. Sci. Mater. Electron. 2007, 18, 347-350. [CrossRef]

6. Anderson, I.E.; Choquette, S.; Reeve, K.T.; Handwerker, C. Pb-free solders and other joining materials for potential replacement of high-Pb hierarchical solders. In Proceedings of the 2018 Pan Pacific Microelectronics Symposium (Pan Pacific), Waimea, HI, USA, 5-8 February 2018. [CrossRef]

7. Zeng, K.; Tu, K. Six cases of reliability study of Pb-free solder joints in electronic packaging technology. Mater. Sci. Eng. R Rep. 2002, 38, 55-105. [CrossRef]

8. Lee, T.-K.; Duh, J.-G. Effect of Isothermal Aging on the Long-Term Reliability of Fine-Pitch Sn-Ag-Cu and Sn-Ag Solder Interconnects With and Without Board-Side Ni Surface Finish. J. Electron. Mater. 2014, 43, 4126-4133. [CrossRef]

9. Yang, L.; Quan, S.; Liu, C.; Shi, G. Aging resistance of the Sn-Ag-Cu solder joints doped with Mo nanoparticles. Mater. Lett. 2019, 253, 191-194. [CrossRef]

10. Qu, M.; Cao, T.; Cui, Y.; Liu, F.; Jiao, Z. Effect of nano-ZnO particles on wettability, interfacial morphology and growth kinetics of Sn-3.0Ag-0.5Cu-xZnO composite solder. J. Mater. Sci. Mater. Electron. 2019, 30, 19214-19226. [CrossRef]

11. Sun, H.; Li, Q.; Chan, Y.C. A study of Ag additive methods by comparing mechanical properties between Sn57.6Bi0.4Ag and 0.4 wt \% nano-Ag-doped Sn58Bi BGA solder joints. J. Mater. Sci. Mater. Electron. 2014, 25, 4380-4390. [CrossRef]

12. Mei, Z.; Morris, J.W. Characterization of eutectic Sn-Bi solder joints. J. Electron. Mater. 1992, 21, 599-607. [CrossRef]

13. Faiz, M.K.; Bansho, K.; Suga, T.; Miyashita, T.; Yoshida, M. Low temperature Cu-Cu bonding by transient liquid phase sintering of mixed Cu nanoparticles and Sn-Bi eutectic powders. J. Mater. Sci. Mater. Electron. 2017, 28, 16433-16443. [CrossRef]

14. Faiz, M.K.; Yamamoto, T.; Yoshida, M. Sn-Bi Added Ag-Based Transient Liquid Phase Sintering for Low Temperature Bonding. In Proceedings of the 2017 5th International Workshop on Low Temperature Bonding for 3D Integration, Tokyo, Japan, 16-18 May 2017; International Integrated Reporting Council: London, UK, 2020.

15. Hu, F.; Zhang, Q.; Jiang, J.; Song, Z. Influences of Ag addition to Sn-58Bi solder on SnBi/Cu interfacial reaction. Mater. Lett. 2018, 214, 142-145. [CrossRef]

16. Stauffer, L.; Würsch, A.; Gächter, B.; Siercks, K.; Verettas, I.; Rossopoulos, S.; Clavel, R. A surface-mounted device assembly technique for small optics based on laser reflow soldering. Opt. Lasers Eng. 2005, 43, 365-372. [CrossRef]

17. Nishikawa, H.; Iwata, N. Formation and growth of intermetallic compound layers at the interface during laser soldering using Sn-Ag Cu solder on a Cu Pad. J. Mater. Process. Technol. 2015, 215, 6-11. [CrossRef]

18. Wentlent, L.A.; Genanu, M.; Alghoul, T. Effects of Laser Selective Reflow on Solder Joint Microstructure and Reliability. In Proceedings of the 2018 IEEE 68th Electronic Components and Technology Conference (ECTC), San Diego, CA, USA, 29 May-1 June 2018; IEEE: Piscataway, NJ, USA, 2018; pp. 425-433. [CrossRef]

19. Joo, H.-S.; Lee, C.-J.; Min, K.D.; Hwang, B.-U.; Jung, S.-B. Mechanical properties and microstructural evolution of solder alloys fabricated using laser-assisted bonding. J. Mater. Sci. Mater. Electron. 2020, 31, 22926-22932. [CrossRef]

20. Chen, H.; Liang, J.; Gao, R.; Li, Y. Laser Soldering of Sn-based Solders with Different Melting Points. In Proceedings of the 21st International Conference on Electronic Packaging Technology, Guangzhou, China, 12-15 August 2020; Guangdong University of Technology: Guangzhou, China, 2020; pp. 1-5. [CrossRef]

21. Kim, J.-O.; Jung, J.-P.; Lee, J.-H.; Suh, J.; Kang, H.-S. Effects of laser parameters on the characteristics of a Sn-3.5 wt.\%Ag solder joint. Met. Mater. Int. 2009, 15, 119-123. [CrossRef]

22. Lee, J.-H.; Park, D.; Moon, J.-T.; Lee, Y.-H.; Shin, D.-H.; Kim, Y.-S. Characteristics of the Sn-Pb eutectic solder bump formed via fluxless laser reflow soldering. J. Electron. Mater. 2000, 29, 1153-1159. [CrossRef]

23. Jaafar, N.B.; Choong, C.S. Effect of Bond Pad Surface Finish on AuSn Solder Bumping Using Laser Solder Jetting. In Proceedings of the 2018 IEEE 20th Electronics Packaging Technology Conference (EPTC), Singapore, 4-7 December 2018; IEEE: Piscataway, NJ, USA, 2018; Volume 821-824.

24. Kim, J.; Myung, W.-R.; Jung, S.-B. Effects of Aging Treatment on Mechanical Properties of Sn-58Bi Epoxy Solder on ENEPIGSurface-Finished PCB. J. Electron. Mater. 2016, 45, 5895-5903. [CrossRef]

25. Chan, Y.C.; So, A.C.K.; Lai, J.K.L. Growth kinetic studies of Cu-Sn intermetallic compound and its effect on shear strength of LCCC SMT solder joints. Mater. Sci. Eng. 1998, 55, 5-13. [CrossRef]

26. Kim, Y.; Kwon, J.; Yoo, D.; Park, S.; Lee, D.; Lee, D. Influence of Nickel Thickness and Annealing Time on the Mechanical Properties of Intermetallic Compounds Formed between Cu-Sn Solder and Substrate. Korean J. Met. Mater. 2017, 55, 165-172. [CrossRef]

27. Shao, H.; Li, M.; Hu, A. The effect of Ag3Sn and Cu3Sn nanoparticles on the IMC morphology of Sn-3.0Ag-0.5Cu solder. In Proceedings of the 2019 20th International Conference on Electronic Packaging Technology (ICEPT); IEEE: Piscataway, NJ, USA, 2019; pp. $1-4$.

28. Vianco, P.T.; Kilgo, A.C.; Grant, R. Solid state intermetallic compound layer growth between copper and hot dipped indium coatings. J. Mater. Sci. 1995, 30, 4871-4878. [CrossRef]

29. Yoon, J.-W.; Lee, C.-B.; Jung, S.-B. Interfacial Reactions Between Sn-58 mass\%Bi Eutectic Solder and (Cu, Electroless Ni-P/Cu) Substrate. Mater. Trans. 2002, 43, 1821-1826. [CrossRef]

30. Gain, A.K.; Zhang, J. Effect of Ag nanoparticles on microstructure, damping property and hardness of low melting point eutectic tin-bismuth solder. J. Mater. Sci. Mater. Electron. 2017, 28, 15718-15730. [CrossRef] 
31. Liu, X.; Huang, M.; Wu, C.M.L.; Wang, L. Effect of Y2O3 particles on microstructure formation and shear properties of Sn-58Bi solder. J. Mater. Sci. Mater. Electron. 2009, 21, 1046-1054. [CrossRef]

32. Yang, F.; Zhang, L.; Liu, Z.-Q.; Zhong, S.; Ma, J.; Bao, L. Properties and Microstructures of Sn-Bi-X Lead-Free Solders. Adv. Mater. Sci. Eng. 2016, 2016, 1-15. [CrossRef] 